vào nghiên cứu thì tuân thủ điều trị kém hơn có thể giả định rằng những bệnh nhân tham gia nghiên cứu của chúng tôi là những bệnh nhân có thể đông cơ điều trị và mức độ sẵn sàng tham gia điều trị chưa cao và có những rào cản trong việc tuân thủ điều trị.

Nghiên cứu của chúng tôi vẫn còn có một số han chế nhất định như các thông tin được thu thập thông qua phỏng vấn trực tiếp, nhiều thông tin được hỏi hồi cứu lại trong khoảng thời gian 6 tháng, điều này có thể dẫn đến sai số báo cáo và sai số nhớ lại. Tuy nhiên, cán bộ nghiên cứu được tâp huấn kỹ về kỹ năng phỏng vấn, khai thác thông tin có thể làm giảm tác động của các sai số trên.

\section{KẾT LUÂN}

Kết quả nghiên cứu cho thây rằng tuân thủ điều trị ARV tương đối tốt trong nhóm bệnh nhân nhận điều trị lồng ghép $A R V$ và điều trị nghiện CDTP bằng buprenorphine. Tuy nhiên, vẩn còn một tỷ lệ nhất định $(20,6 \%)$ chưa đạt ngưỡng tuân thủ điêu trị ARV. Kết quả này đã dẫn đến các khuyến cáo hỗ trợ tuân thủ điều trị ARV như cung cấp liều điều trị nghiện chất phù hợp, thay đổi hành vi sử dụng chất bằng cách kết hợp các liệu pháp tâm lý hành vi. Đồng thời tăng cường các biên pháp hỗ trợ tuân thủ ARV như gửi tin nhắn điện thoại và sự hỗ trợ của gia đình trong quá trình điều trị.
TÀI LIÊU THAM KHẢO

1. UNODC (2020), World Drug Report 2020,

2. Cuc phòng, chống HIV/AIDS (2020), Báo cáo kểt quả phòng, chống HIV/AIDS năm 2019 và nhiệm vụ trọng tâm năm 2020,

3. Low A.J., Mburu G., Welton N.J., et al. (2016). Impact of Opioid Substitution Therapy on Antiretroviral Therapy Outcomes: A Systematic Review and Meta-Analysis. Clin Infect Dis Off Publ Infect Dis Soc Am, 63(8), 1094-1104.

4. Basu S., Smith-Rohrberg D., Bruce R.D., et al. (2006). Models for integrating buprenorphine therapy into the primary HIV care setting. Clin Infect Dis Off Publ Infect Dis Soc Am, 42(5), 716-721.

5. Diep N.B., Korthuis P.T. Trang N.T., et al. (2016). HIV patients' preference for integrated models of addiction and hiv treatment in vietnam. J Subst Abuse Treat, 69, 57-63.

6. Sethi A.K., Celentano D.D., Gange S.J., et al. (2003). Association between adherence to antiretroviral therapy and human immunodeficiency virus drug resistance. Clin Infect Dis Off Publ Infect Dis Soc Am, 37(8), 1112-1118.

7. Moatti J.P., Carrieri M.P., Spire B., et al. (2000). Adherence to HAART in French HIV-infected injecting drug users: the contribution of buprenorphine drug maintenance treatment. The Manif 2000 study group. AIDS Lond Engl, 14(2), 151-155.

8. Ortego C., Huedo-Medina T.B., Llorca J., et al. (2011). Adherence to highly active antiretroviral therapy (HAART): a meta-analysis. AIDS Behav, 15(7), 1381-1396.

9. Tran B.X., Nguyen L.T., Nguyen N.H., et al. (2013). Determinants of antiretroviral treatment adherence among HIV/AIDS patients: a multisite study. Glob Health Action, 6(1), 19570.

\title{
KÊTT QUẢ ĐIỀU TRI GÃY KÍN ĐẦU DƯỚI XƯO'NG QUAY BẰNG NẮN BÓ BộT TẠI BỆNH VIỆN THỐNG NHẤT
}

\author{
Nguyễn Thị Thắm*, Nguyễn Bảo Lục*, Võ Thành Toàn*
}

\section{TÓM TẮT}

Mục tiêu: Đánh giá kết quả điều trị gãy đâu dưới xương quay bằng nắn bó bột tại khoa Chấn thương Chỉnh hình, Bệnh viện Thống Nhất. Phương pháp nghiên cứu: Nghiên cứu tiển cứu mô tả 64 bệnh nhân phát hiện có gãy kín đầu dưới xương quay được điều tri kéo nắn bó bôt và tái khám tai Bênh viển Thống Nhất từ 03/2018 đến 12/2020. Kết quả: Tất cả bệnh nhân được theo dõi và đánh giá sau bó bột 1 tuần, 1 tháng, 3 tháng, 6 tháng trên lâm sàng, 100\% bệnh nhân liển xương, 53,1\% bệnh nhân phục hồi giải

\section{*Bệnh viện Thống Nhất}

Chịu trách nhiệm chính: Võ Thành Toàn

Email: vothanhtoan1990@yahoo.com

Ngày nhân bài: 19.11.2020

Ngày phản biện khoa học: 24.12.2020

Ngày duyệt bài: 5.01.2021 phẫu đạt tốt và rất tốt, 73,5\% bệnh nhân phục hồi chức nắng đạt tốt và rất tốt. Kết luận: Điều trị gãy kín đầu dưới xương quay bằng kéo nắn bó bột vẫn cho hiệu quả điều trị phục hồi giải phẫu và chức năng tốt.

Tư khóa: Gãy kín đầu dưới xương quay; điều trị bảo tồn bằng kéo nắn bó bột.

\section{SUMMARY}

\section{THE TREATMENT RESULTS OF DISTAL RADIUS CLOSED FRACTURE BY REDUCTION AND CASTING AT THONG NHAT HOSPITAL}

Objective: To evaluate the results of the treatment closed fracture of the distal radius by reduction and casting at Thong Nhat Hospital. Methods: The prospective, descriptive study was conducted on 64 patients had closed fractures of the distal radius with reduction and casting at Thong Nhat hospital, from March 2018 to December 2020. Results: All patients were followed after casting at 1 
week, 1 month, 3 months, 6 months and evaluated on clinical exam, $100 \%$ of patients had a union, $53,1 \%$ of patients had good and very good on anatomical recovery, $73,5 \%$ of patients had good and very good on functional rehabilitation. Conclusion: The reduction and casting treatment on the closed fracture of distal radius still effective in recovering anatomical and functional rehabilitation as good and very good.

Keywords: Closed fracture of the distal radius, reduction and casting conservation treatment.

\section{I. ĐẶT VẤN ĐỀ}

Gãy kín đầu dưới xương quay là loại gãy xương chi trên thường gặp nhất trong chấn thương chỉnh hình với $26 \%$, chiếm $17 \%$ các trường hợp gãy xương trong cấp cứu, $8 \%$ trong tổng số gãy xương và chiếm $50 \%$ trường hợp gãy xương ở cẳng tay [2].

Năm 2004, Anzarut A. nghiên cứu 74 bệnh nhân gãy đầu dưới xương quay trên 50 tuổi được nắn kín, bất động bột và phân làm 2 nhóm: kết quả $X$ - quang chấp nhận được và không chấp nhận; Tác giả nhận thấy $64 \%$ bệnh nhân cho kết quả $X$ - quang chấp nhận được nhưng chức năng của tay và sự hài lòng cũng không cao hơn so với nhóm còn lại; $59 \%$ bênh nhân cho biết hài lòng hoặc rất hài lìng về chức năng sau 6 tháng [5]. Luận văn bác sỹ nội trú của Trần Ngọc Lĩnh: "Điều trị gãy đầu dưới xương quay kiểu Colles bằng bột kín chức năng theo nguyên lý Sarmiento" năm 2007 với 31 bệnh nhân cho kết quả $74 \%$ phục hồi giải phẫu chấp nhận được, trong đó $32 \%$ loại tốt và $42 \%$ loại khá, tỉ lệ can lệch xấu 26\% [2].

Đối với gãy kín đầu dưới xương quay có nhiều phương pháp điều trị, việc lựa chọn phương pháp điều trị còn tùy thuộc vào nhiều yếu tố như: yếu tố tại vị trí gãy, yếu tố toàn thân (giới tính, tuổi, bệnh nội khoa sẵn có...), nhu cầu lao động của người bệnh, khả năng tài chính, cũng như khả năng trang thiết bị y tế hiện có tại cơ sở [8]. Với phát triển hiện nay của y học, khoa Chấn thương Chỉnh hình Bệnh viện Thống Nhất, bên cạnh phẫu thuật kết hợp xương gãy kín đầu dưới xương quay, chúng tôi vẫn không đánh giá thấp viêc điều trị bảo tồn bằng kéo nắn bó bôt. Do đó chúng tôi nghiên cứu đề tài này nhằm: đánh giá kết quả điều trị gãy đầu dưới xương quay bằng kéo nắn bó bột tại Bệnh viện Thống Nhất.

\section{II. ĐỐI TƯỢNG VÀ PHƯƠNG PHÁP NGHIÊN CỨU}

Đối tượng: Hồ sơ bệnh án của 64 bệnh nhân phát hiện có gãy kín đầu dưới xương quay được điều trị kéo nắn bó bột tại Bệnh viện Thống Nhất từ 03/2018 đến $12 / 2020$.

* Tiêu chuẩn chọn bệnh: BN đồng ý tham gia nghiên cứu và có các tiêu chuẩn như sau: BN $\geq 16$ tuổi, chấn thương mới gặp $<1$ tuần, có gãy kín đầu dưới xương quay trên phim $X$ quang (phân loại $A O)$, có thể kèm theo gãy mỏm trâm trụ, bệnh nhân có chỉ định điều trị bảo tồn, có thông tin địa chỉ rõ ràng để theo dõi, bệnh nhân đồng ý với phương pháp điều trị và hợp tác tốt.

* Tiêu chuẩn loại trừ: bệnh nhân không đồng ý tham gia nghiên cứu, bệnh nhân gãy xương bệnh lý, gãy hở đầu dưới xương quay, gãy kèm theo tổn thương mạch máu thần kinh, bệnh nhân không có chỉ định điều trị bảo tồn.

$>$ Chỉ định điêuu trị bảo tôn [6],[9]:

- Gãy ít di lệch, không thấu khớp, vững (chồng ngắn $<5 \mathrm{~mm}$ kèm góc nghiêng lòng dưới 5 độ, góc nghiêng trụ dưới 20 độ) và có thể nắn kín được. Theo thuyết 3 cột của Rili và Reagazzoni [9].

- Nhu cầu làm việc thấp.

- Nhiều bênh lý nội khoa kèm theo.

Phương pháp nghiên cứu: Tiến cứu mô tả hồ sơ 64 trường hợp bệnh nhân thỏa tiêu chuẩn chọn bệnh tại Bệnh viện Thống Nhất từ tháng 03/2018 đến tháng 12/2020.

Bệnh nhân được khai thác bệnh sử xác định thời điểm tổn thương, nguyên nhân, chẩn đoán, xử trí trước đó. Chụp $\mathrm{X}$ - quang cố tay bị chấn thương thẳng nghiêng. Theo dõi sau kéo nắn bó bột, tập vật lý trị liệu và tái khám.

Phương pháp kéo nắn, bó bột theo Boehler [1]. Đánh giá sau bó bột: chụp $\dot{X}$ - quang kiểm tra ngay sau khi bó bôtt, nếu $X$ - quang không chấp nhận được thì cắt bột và nắn lại ngay. Di lệch sau nắn được đánh giá theo tiêu chuẩn của Haas và De la Caffiniere [7]:

Bảng 2.1. Đánh giá kêt quả gãy ĐDXQ theo Haas và De la Caffiniere

\begin{tabular}{|c|c|c|c|}
\hline & $\begin{array}{c}\text { Góc } \\
\text { nghiêng trụ }\end{array}$ & $\begin{array}{c}\text { Chi số } \\
\text { quay-trụ }\end{array}$ & $\begin{array}{c}\text { Góc nghiêng } \\
\text { lòng }\end{array}$ \\
\hline Rất tốt & $20-30^{0}$ & $-2-0 \mathrm{~mm}$ & $10-20^{0}$ \\
\hline Tốt & $10-20^{0}$ & $0-2 \mathrm{~mm}$ & $0-10^{0}$ \\
\hline Khá & $0-10^{0}$ & $2-4 \mathrm{~mm}$ & $-10-0^{0}$ \\
\hline Xấu & $<0^{0} ;>30^{0}$ & $>4 \mathrm{~mm}$ & $<-10^{0} ;>20^{0}$ \\
\hline
\end{tabular}

Sau bó bột bênh nhân được theo dõi và hướng dẫn theo dối biến chứng sau bó bột (nhất là chèn ép bột). Tập vận động gồng cơ trong bột ngay sau khi bột khồ tốt, tập không gây đau đớn. Sau đó tập vận động nắm duổi nhe các ngón hết tầm, gồng cơ trong bột, cử động khớp vai. Khi tháo bột: chườm ấm hoặc ngâm ngước ấm cẳng bàn tay, xoa bóp cẳng bàn tay, tập gập duỗi, nghiêng trụ, nghiêng quay cổ tay và sấp ngửa cẳng tay, tập nắm bàn tay. Tập vắt khăn, rửa mặt, chải tóc. Sau 12 tuần có thể tập xách 
đồ nặng 2-3kg hay chống tay lúc ngồi đứng dậy.

Đánh giá và theo dõi:

- Theo dõi 48 giờ sau bó bột, tái khám sau 1 tuần, 4 tuần, 12 tuần, 24 tuần.

- Trong 48 giờ theo dõi chèn ép bột.

- Sau 1 tuần: theo dõi lỏng bột, chụp lại X quang có di lệch thứ phát trong bột không.

- Sau 4 tuần: kiểm tra lành xương trên lâm sàng, kiểm tra vị trí ổ gãy còn đau hay không, còn cử động bất thường hay không; Có can xương bắc cầu trên $X$ - quang thì sẽ tháo bột đeo nẹp vải.

- Sau 12 tuần và sau 24 tuần: BN được chup $X$ - quang kiểm tra và đánh giá kết quả phục hồi giải phẫu cũng như chức năng sau cùng.

- Đánh giá chức năng biên độ các khớp cổ tay, khuỷu tay, nắm bàn tay, vị trí và mức độ đau của tay theo hệ thống đánh giá kết quả của Green và O'Brien được Cooney và cộng sự cải tiến [9].

- Rất tốt: 90 - 100 điểm.

- Tốt: 80 - 89 điểm.

- Khá: 65 - 79 điểm.

- Xấu: < 65 điểm.

\section{KẾT QUẢ NGHIÊN CỨU}

\subsection{Tổng quan:}

Bảng 3.1. Phân bố bệnh nhân theo giới tính $(n=64)$

\begin{tabular}{|c|c|c|c|}
\hline Giới tính & Nam & Nữ & Tống \\
\hline Số BN & 18 & 46 & 64 \\
\hline Tỷ lệ \% & 28,1 & 71,9 & 100,0 \\
\hline
\end{tabular}

Tỷ lệ bệnh nhân nam gãy đầu dưới xương quay ít hơn nữ, tỷ lệ nam/nữ $=1 / 2,6$

Bảng 3.2. Phân bố bệnh nhân theo tuổi $(n=64)$

\begin{tabular}{|c|c|c|c|c|}
\hline $\begin{array}{c}\text { Nhóm } \\
\text { tuối }\end{array}$ & $\begin{array}{c}\mathbf{1 6}- \\
\mathbf{3 9}\end{array}$ & $\begin{array}{c}\mathbf{4 0 - 5 9} \\
\text { tuổi }\end{array}$ & $\begin{array}{c}\mathbf{\geq} \mathbf{6 0} \\
\text { tuổi }\end{array}$ & Tổng \\
\hline Số BN & 6 & 28 & 30 & 64 \\
\hline Tỷ lệ (\%) & 9,4 & 43,8 & 46,8 & 100,0 \\
\hline
\end{tabular}

Phân bố nhiều nhất ở nhóm bệnh nhân từ $\geq$ 60 tuổi, chiếm tỷ lệ 46,8\%. Độ tuổi 40 - 59 chiếm tỉ lệ ít hơn không nhiều với 43,8\%.

Bảng 3.3. Cơ chế chấn thương $(n=64)$

\begin{tabular}{|c|c|c|c|c|c|}
\hline $\begin{array}{c}\text { Nguyên } \\
\text { nhân }\end{array}$ & TNGT & TNSH & TNTT & TNLĐ & Tổng \\
\hline Số BN & 24 & 35 & 1 & 4 & 64 \\
\hline Tỷ lệ (\%) & 37,5 & 54,7 & 1,6 & 6,2 & 100,0 \\
\hline
\end{tabular}

Chấn thương gãy đầu dưới xương quay do tai nạn sinh hoạt chiếm tỷ lệ cao nhất $(54,7 \%)$, sau đó là tai nạn giao thông $(37,5 \%)$, rồi đến tai nan lao động $(6,2 \%)$, và cuối cùng là tai nạn thể thao $(1,6 \%)$.

\section{bó bột:}

Trong tổng 64 trường hợp nghiên cứu, các bệnh nhân đều được chụp $X$ - quang để phân độ gãy kín đầu dưới xương quay.

Bảng 3.4. Phân bố bệnh nhân gãy đầu dưới xương quay theo phân loại $A O(n=64)$

\begin{tabular}{|c|c|c|}
\hline Loại gãy & Số bệnh nhân & Tỷ lệ \% \\
\hline A2 & 26 & 40,6 \\
\hline A3 & 21 & 32,8 \\
\hline B1 & 10 & 15,6 \\
\hline B2 & 4 & 6,3 \\
\hline B3 & 3 & 4,7 \\
\hline C1 & 0 & 0 \\
\hline Tống & $\mathbf{6 4}$ & $\mathbf{1 0 0 . 0}$ \\
\hline
\end{tabular}

Trong số bệnh nhân gãy đầu dưới xương quay không phạm khớp loại $A 2, A 3$ chiếm tî lệ $73,4 \%$; $B 1, B 2$, B3 chiếm tî lệ $26,6 \%$; $C 1$ chiếm tỉ lệ $0 \%$.

3.3. Kết quả sau kéo nắn bó bột trên bệnh nhân gãy kín đâu dưới xương quay:

Trong 64 bệnh nhân nghiên cứu, chúng tôi dựa vào bảng đánh giá trên phim $X$ - quang theo JL Haas và JY de la Caffinière, ghi nhận sau lần khám cuối cùng:

Bảng 3.5. Kết quả $X$ - quang theo bảng đánh giá của Haas và De la Caffiniere $(n=64)$

\begin{tabular}{|c|c|c|}
\hline Kết quả & Số bệnh nhân & Tỉ lệ (\%) \\
\hline Rất tốt & 7 & 10,9 \\
\hline Tốt & 27 & 42,2 \\
\hline Khá & 21 & 32,8 \\
\hline Xấu & 9 & 14,1 \\
\hline Tống & $\mathbf{6 4}$ & $\mathbf{1 0 0 . 0}$ \\
\hline
\end{tabular}

Kết quả $X$ - quang tốt và rất tốt đạt 53,1 \%, khá 32,8\%, xấu 14,1\%.

Bảng 3.6. Kết quả lành xương $(n=64)$

\begin{tabular}{|c|c|c|}
\hline Kết quả & Số bệnh nhân & Tỉ lệ (\%) \\
\hline Lành xương & 64 & 100,0 \\
\hline Không lành xương & 0 & 0 \\
\hline Tống & $\mathbf{6 4}$ & $\mathbf{1 0 0 , 0}$ \\
\hline
\end{tabular}

Nhóm nghiên cứu ghi nhận $100 \%$ bệnh nhân liền xương sau $8-12$ tuần nắn bó bột dựa trên lâm sàng và $X-$ quang quy ước.

Kết quả phục hồi chức năng sau lần khám cuối cùng được đánh giá cơ năng và thực thể, sau đó phân loại theo thang điểm Green và O'Brien được Cooney và cộng sự cải tiến:

* Cơ năng: Đánh giá theo chủ quan bệnh nhân có 42 ca không đau, 20 đau nhẹ chấp nhận được cổ tay sau điêu trị $(31,3 \%), 2$ ca còn lại đau vừa và đau nhiều khi làm việc nặng. Tất cả bệnh nhân đều trở lại công việc cũ, 18 ca bị giới hạn trong công việc

* Thực thể: 
Bảng 3.7. Biên độ vận động của cổ tay $(n=64)$

\begin{tabular}{|c|c|c|c|c|}
\hline \multirow{2}{*}{ Tư thế } & \multicolumn{3}{|c|}{ Biên độ vận động (độ) } \\
\cline { 2 - 5 } & $\begin{array}{c}\text { Trung } \\
\text { bình }\end{array}$ & $\begin{array}{c}\text { Trung } \\
\text { vị }\end{array}$ & $\begin{array}{c}\text { Nhó } \\
\text { nhất }\end{array}$ & $\begin{array}{c}\text { Lớn } \\
\text { nhất }\end{array}$ \\
\hline Gấp cố tay & 77.3 & 75 & 55 & 90 \\
\hline Duôii cố tay & 71,0 & 75 & 45 & 90 \\
\hline Nghiêng quay & 12,0 & 15 & 10 & 25 \\
\hline Nghiêng trụ & 26,0 & 25 & 15 & 35 \\
\hline Sấp & 75,0 & 80 & 40 & 90 \\
\hline Ngửa & 86,5 & 80 & 40 & 90 \\
\hline
\end{tabular}

Bảng 3.8. Kết quả phục hồi chức năng theo thang điểm Green và O'Brien được Cooney và cộng sự cải tiến $(n=64)$

\begin{tabular}{|c|c|c|}
\hline Kết quả & Số bệnh nhân & Tỉ lệ (\%) \\
\hline Rất tốt & 28 & 43,8 \\
\hline Tốt & 19 & 29,7 \\
\hline Khá & 15 & 23,4 \\
\hline Xấu & 2 & 3,1 \\
\hline Tống & $\mathbf{6 4}$ & $\mathbf{1 0 0 . 0}$ \\
\hline
\end{tabular}

Trong tống số 64 bệnh nhân nghiên cứu có 47 bệnh nhân đạt được chức năng tốt và rất tốt chiếm tỉ lệ $73,5 \%$, bệnh nhân chức năng xấu chiếm $3,1 \%$ rơi vào 2 ca gãy độ $B 3$.

3.4. Đánh giá các biến chứng: Chúng tôi ghi nhận không ca nào bị chèn ép bột, không lành xương, tổn thương thần kinh, tổn thương gân hay khớp giả. Trong 64 ca nghiên cứu có 12 trường hợp có biến chứng sau bó như can lệch $10 \mathrm{ca}$, trật hoặc lỏng khớp quay trụ dưới $2 \mathrm{ca}$.

\section{BÀN LUÂ̂N}

Nhóm nghiên cứu ghi nhận, trong 64 bệnh nhân thì nữ chiếm đa số; tỉ lệ nam/nữ $=1 / 2,6$. Đa phần bệnh nhân nhóm ghi nhận từ 40 tuổi trở lên $(90,6 \%)$, chấn thương thường gặp chủ yếu là tai nạn sinh hoạt và tai nạn giao thông. Điều này phù hợp với tình trạng lao động cần tham gia giao thông nhiêu ở nhóm tuổi, bên cạnh đó khả năng xử lý tình huống khi té ngã, cũ̃ng như tình trạng loãng xương sau 60 tuổi cũng góp phần gãy xương dù lực tác động nhỏ.

Trong mẫu nghiên cứu của chúng tôi, gãy xương không phạm khớp loại $A 2, A 3$ chiếm tỉ lệ $73,4 \%$; $B 1, B 2$, B3 chiếm tỉ lệ $26,6 \%$; $C 1$ chiếm tỉ lệ $0 \%$. Hầu hết các trường hợp đều được khám và bó bột dưới 1 tuần kể từ khi chấn thương. Kết quả $X$ - quang sau bó bột của chúng tôi theo bảng đánh giá của JL Hass và JY De La Caffinière với $53,1 \%$ đạt tốt và rất tốt; khá $32,8 \%$ gần tương đương với các tác giả như Trần Ngọc Lĩnh [2], Phan Hữu Trọng [4], số trường hợp can lệch ít hơn các tác giả do số mẫu nhận được nhỏ hơn và ít trường hợp gãy phức tạp.

Chúng tôi đánh giá kết quả lành xương dựa vào phim $X$ - quang: các bè xương bắc cầu qua đoạn gãy, không thấy khe gãy, hay khe gãy hẹp lại dần, mờ dân và mất đi là dấu hiệu nhận biết quá trình lành xương hình thành. Xương vùng gãy có mật độ tương tự với các xương lân cận. Tất cả các ca nghiên cứu đều lành xương, tương tự với kết quả của các tác giả khác

Trong mẫu nghiên cứu của chúng tôi, tất cả bệnh nhân đều trở lại các công việc như trước; trong đó có 20 bệnh nhân đau nhẹ ở tay chấn thương nhưng chấp nhận được, 2 bệnh nhân đau vừa và đau nhiều khi làm việc nặng. Có 18 ca bị giới hạn vận động trong mọi công việc. Vì nghiên cứu chúng tôi thực hiện trên mọi lứa tuổi từ 16 trở lên, đa phần công việc đa dạng nên sau điều trị phần lớn bệnh nhân còn sử dụng cổ tay nhiều trong công việc và sinh hoạt. Biên độ vận động của cổ tay được đánh giá bằng thước đo góc, trong các động tác: gấp - duỗi cổ tay, nghiêng quay - nghiêng trụ cổ tay, sấp - ngửa cẳng tay. Nhóm ghi nhận kết quả gần tương tự với các tác giả khác. Kết quả phục hồi chức năng theo thang điểm của Green và O'Brien cải biên của chúng tôi có tỷ lệ cao với $73,5 \%$ tốt và rất tốt; kết quả gần tương đương với những tác giả khác. Nói lên tính hiệu quả của kéo nắn bó bột trong điêu trị bảo tồn gãy kín đầu dưới xương quay.

\section{KẾT LUẬN}

Qua 64 trường hợp nghiên cứu chúng tôi thây rằng gãy kín đầu dưới xương quay được điều trị bảo tồn bằng kéo nắn bó bột vẫn cho kết quả liền xương $100 \%$; Dựa trên bảng đánh giá của Hass và De la Caffiniere cho kết quả giải phẫu tốt và rất tốt chiếm tỉ lệ 53,1\%; Dựa trên thang điểm Green và $\mathrm{O}^{\prime} B r i e n$ cho kết quả phục hồi chức năng $73,5 \%$ tốt và rất tốt; $3,1 \%$ trường hợp xấu rơi vào gãy độ B3. Vì vậy gãy kín đầu dưới xương quay mặc dù ở cơ sở đây đủ điều kiện phẫu thuật thì việc điều trị bảo tồn bằng kéo nắn bó bột vẫn cho hiệu quả điều trị phục hồi giải phẫu và chức năng tốt. Từ đó góp phần giảm bớt gánh nặng cho bệnh nhân và gia đình, góp phần xây dựng và phát triển xã hội.

\section{TÀI LIẸU THAM KHẢO}

1. Bohler L, [Nguyễn Quang Long dịch], (1985), "Gãy đầu dưới xương quay", Kỹ thuật điêuu trị gãy xương, tập II, tr. 231 - 244 và tập IV, tr. 255 261.

2. Trần Ngoc Lĩnh (2007), "Điều trị gãy kín đầu dưới xương quay kiểu Colles bằng bột kín chức năng theo nguyên lý Sarmiento", Luận văn bác sỹ nội trú chấn thương chỉnh hình, Đại học Y dược TP. Hồ Chí Minh.

3. Vũ Xuân Thành (2004), "Điều trị gãy đầu dưới xương quay bằng nẹp ốc", Luận văn bác sỹ nội trú 
chấn thương chỉnh hình, Đại học Y dược TP. Hồ Chí Minh.

4. Phan Hữu Trong (2018), "Đánh giá kết quả điều trị gãy đâu dưới xương quay bằng nắn bó bột tại trung tâm y tế Đức Huệ - Long An", Luận văn bác sỹ chuyên khoa II chấn thương chỉnh hình, Đại học Y khoa Pham Ngoc Thach.

5. Anzarut A. (2004), "Radiologic and patient reported functional outcomes in an elderly cohort with conservatively treated distal radius fractures", Journal of Hand Surgery, 16A, pp. $1-10$.

6. Cohen MS., McMurtry RY., Jupiter JB, (1998), "Fracture of the distal radius, Skeletal trauma",
W.B. Saunders Company, $2^{\text {nd }}$ Edition, vol.2, pp. $1383-1417$.

7. Haas JL., De la Caffiniere JY., (1985), "Fixation of distal radial fractures: intramedullary pinning versus external fixation", Fracture of the distal radius, Lippincott Company, Philadelphia, pp. $229-239$.

8. Jupiter JB, (1991), "Current concepts review fractures of the distal end of the radium", Journal of Bone and Joint Surger, 73-A, pp. $461-469$.

9. Rikli DA, Regazzoni P, (1996), "Fracture of the distal end of the radius treated by internal fixation and early function: A preliminary report of 20 cases", Journal of Bone and Joint Surgery, 78-B, pp. $588-592$.

\section{PHẪU THUÂTT NộI SOI MộT ĐƯỜNG RACH ĐIỀU TRI DI TÂ̂T RUỘT QUAY BÂT THƯỜNG Ở' TRẺ SƠ SINH}

\section{TÓM TẮT}

Mục tiêu: Mô tả kỹ thuâtt phẫu thuật nội soi môt đường rạch (PTNSMDR) điều trị di tật ruôt quay bẩt thường (DTRQBT) ở trẻ sơ sinh. Phương pháp nghiên cứu: Báo cáo 1 ca bệnh và tổng quan y văn. Kết quả: Bệnh nhân là trẻ nam 8 ngày tuối, cân nặng $3,3 \mathrm{~kg}$, nhập viện do nôn dịch vàng và vàng da tẳng bilirubin tự do. Dưa trên bệnh cảnh lâm sàng và chẩn đoán hình ảnh, bệnh nhân được chẩn đoán DTRQBT xoắn trung tràng (không có hoại tử ruột) và được chỉ đinh điêu trị phẫu thuất. Chúng tôi rach da đường vòng cung dưới rốn, đặt 1 trocar $5.5 \mathrm{~mm}$ và 2 trocar $3.5 \mathrm{~mm}$ trong phạm vi 1 vết rạch này. Dùng optic $30^{\circ}$ và dụng cụ nội soi thẳng thông thường. Trong mổ phát hiện xoắn trung tràng 360 độ, ruôt hồng không bị giảm tưới máu. Tiến hành thực hiện phẫu thuật Ladd: tháo xoắn, cắt dây chằng Ladd, tải rộng mạc treo, xếp lại ruột non sang phải, đại tràng sang bển trái và cắt ruột thừa. Khồng có mất máu đáng kể, không có tai biến trong mổ. Thời gian mổ là 90 phút. Trẻ phục hổi lưu thông tiêu hóa tốt và được cho ăn đường miệng từ ngày 3 sau mổ. Tuy nhiên BN bị viêm phế quản phổi phải điều trị kháng sinh và ra viện ngày 9 sau mố. Theo dõi 9 tháng sau mổ, BN khổng còn triệu chứng. Thẩm mỹ sau mổ là rất tốt, $\mathrm{BN}$ coi như khồng nhìn thấy sẹo mổ. Kết luận: Kỹ thuật của chúng tôi PTNSMĐR điều trị DTRQBT ở trẻ sơ sịnh là có tính khả thi, an toàn và có kết quả thẩm mỹ cao.

Từ khóa: Phẫu thuật nội soi một đường rạch, ruột quay bất thường, trẻ sơ sinh

\section{SUMMARY}

*Bệnh viện Đa khoa Xanh Pôn

Chịu trách nhiệm chính: Trân Ngọc Sơn

Email: drtranson@yahoo.com

Ngày nhận bài: 16.11.2020

Ngày phản biên khoa họ: 28.12.2020

Ngày duyệt bài: 7.01.2021

\section{Trần Ngọc Sơn*, Nguyễn Thị Hồng Vân* SINGLE INCISION LAPAROSCOPIC SURGERY FOR MALROTATION IN A NEONATE}

Objectives: We present our technique of single incision laparoscopic surgery (SILS) for malrotation in a neonate. Methods: This is a case report and review of the literature. Results: The patient was a eightday-old boy admitted to our department for bilious vomiting and jaundice (indirect hyperbilirubinemia). Based on the clinical presentations and imaging studies, the diagnosis of malrotation was made and the patient was indicated for laparoscopic surgical repair. An inferior curvilinear umbilical incision was made. One $5.5 \mathrm{~mm}$ trocar and two $3.5 \mathrm{~mm}$ trocars were placed at different points in the same incision. A standard $5 \mathrm{~mm}, 30^{\circ}$ laparoscope and conventional straight laparoscopic instruments were used. Intraoperatively we found malrotation with $360^{\circ}$ midgut volvulus without vascular compromise. A Ladd's procedure was performed: derotation, division of the Ladd's ligament, widening of the mesentery, repositioning of the bowels (the small bowel on the right and the large bowel on the left) and appendectomy. There was no significant blood loss, no intraoperative complications. The operative duration was 90 minutes. The patient resumed oral feeding on postoperative day 3, but suffered from bronchopneumonia. He was treated with antibiotics and was discharged on POD 9. At a follow up 9 months he was asymptomatic. The postoperative cosmesis was excellent as the patient had no visible scar. Conclusions: Our technique of SILS for malrotation in neonates can be feasible, safe with excellent post-operative cosmesis.

Keywords: Single incision laparoscopic surgery, malrotation, neonate.

\section{I. ĐĂT VẤN ĐỀ}

Dị tật ruột quay bất thường (DTRQBT) là do rối loạn quá trình xoay và cố định của trung tràng trong thời kỳ bào thai với kết quả là vi trí bất thường của đoạn chuyển tiếp tá tràng hỗng 